\title{
SEGUIR CARREIRA (OU NÃO) EM UMA EMPRESA FAMILIAR
}

Elisa Bornhausen CUnHa HeHN - elisa@brascopo.com.br

Universidade do Vale do Itajaí, Itajaí - SC, Brasil

DEISE LOHN - deise.lohn@ gmail.com

Universidade do Vale do Itajaí, Itajaí - SC, Brasil

Daniela Cardoso Pereira - danicardoso4@ hotmail.com

Universidade do Vale do Itajaí, Itajaí - SC, Brasil

Alissane MignONi - alissanemignon@ hotmail.com

Universidade do Vale do Itajaí, Itajaí - SC, Brasil

SidNeI VIEIRA MARINHO - sidnei@ univali.br

Universidade do Vale do Itajaí, Itajaí - SC, Brasil

Carolina tem 27 anos, é casada e formada em Turismo e Hotelaria. Há quatro anos trabalha na empresa de seu pai, uma distribuidora de produtos descartáveis, que possui uma administração familiar, está no mercado há cinco anos, e onde trabalham sua mãe, seu irmão, seu marido e o próprio pai. Hoje, Carolina é responsável pelo setor financeiro e, por não ter experiência na área, foi buscar qualificação. Atualmente, cursa a primeira fase de graduação em Ciências Contábeis e especialização em Finanças Empresariais.

Devido à busca por essa qualificação, Carolina pôde perceber os conflitos que existiam na gestão familiar. Com o aprendizado proporcionado pelos cursos, começou a mudar as rotinas e os hábitos da empresa, e essas mudanças fizeram com que Carolina repensasse sua carreira profissional.

\section{Vida familiar e profissional}

Carolina nasceu em Florianópolis, Santa Catarina, onde sempre morou com seus pais e o irmão mais novo, Diogo. A mãe é formada em Direito, o pai, em Representação Comercial, o irmão, em Administração e Marketing, e Carolina, em Turismo e Hotelaria. Quando optou por este curso, seu maior desejo era trabalhar com "pessoas", pois achava que não tinha vocação para os "números".

Por morar em uma cidade turística, acreditou que teria grandes oportunidades, pois o mercado de trabalho nessa área estava crescendo, assim como a estrutura de turismo no Brasil. Observava opções de grandes hotéis, empresas de eventos e agências de viagens. Sabia que as melhores ofertas eram fora da cidade, mas acreditou que pudesse fazer a diferença em Florianópolis. 
Durante o curso, Carolina percebeu que as coisas não seriam tão fáceis quanto pareciam no início. Além da necessidade de longas jornadas de trabalho, a profissão não remunerava de acordo com suas expectativas, mas, por ser determinada, depois de iniciar o curso, decidiu não trocá-lo. Concluiria a faculdade de Turismo e Hotelaria e tentaria seguir carreira, nem que, depois, fosse necessário realizar outro curso. Fez a faculdade entre os anos de 2001 e 2005, e seu trabalho de conclusão de curso foi sobre marketing para agências de viagens, voltado para a área que estava apostando como profissão naquele momento.

Trabalhou com postos turísticos e em uma empresa que organizava eventos, até chegar a uma agência de viagens, onde ficou por três anos. No início, parecia o emprego perfeito, a remuneração era boa para quem se dedicava, apesar de não ter concluído a faculdade, e ainda era uma chance de colocar em prática todos os ensinamentos teóricos vivenciados em sala de aula.

Com o tempo, no entanto, o emprego foi se revelando mais desgastante do que ela previra. Trabalhar com um produto subjetivo, como uma viagem dos sonhos, uma lua-de-mel e ou, até mesmo (re)começar a vida em outro país, tudo isso exigia demais e nem sempre o resultado era o esperado por ambas as partes. Foram várias noites sem dormir, imaginando se o passageiro tinha conseguido passar pela imigração em determinado país, se o hotel escolhido por um casal para a luade-mel atendia às expectativas, se a bagagem completa tinha chegado junto com o grupo e se os voos estavam no horário, principalmente aqueles que dependiam de conexões.

Foram três anos de exigências, não só do emprego mas também de si mesma. Ainda que a prestação de serviços dependesse quase exclusivamente de outras pessoas, Carolina cobrava muito de si própria e ficava incomodada quando recebia uma reclamação de algum problema relacionado com as viagens dos clientes.

Foi nesse período que seu pai abriu a empresa onde ela viria a trabalhar. O pai de Carolina, Sr. Ismael, trabalhou em uma distribuidora de alimentos como representante comercial durante 31 anos e foi despedido por não ter mais o perfil exigido pela empresa. Esta era a oportunidade de realizar seu grande sonho, o de ter seu próprio negócio, para o qual sempre lhe faltava coragem. Sendo assim, com o dinheiro da rescisão em mãos, resolveu que era hora de abrir seu próprio negócio, deixando a insegurança de lado e considerando sua experiência profissional, que consistia em vender e atender os clientes. Sr. Ismael já conhecia o comportamento dos compradores de supermercados e, durante sua longa carreira, acabou criando vínculos com alguns clientes. Utilizou isso a seu favor para continuar atuando no ramo de distribuição e conseguiu, dessa forma, manter seus contatos e a carteira de clientes.

Em 2005, a empresa iniciava suas atividades. No primeiro momento, além do pai, foram trabalhar na empresa a mãe, o irmão e Alberto, noivo de Carolina.

Alberto já havia trabalhado com o Sr. Ismael anteriormente, e lhe apoiou na constituição do novo negócio, por isso foi um dos primeiros funcionários. Criava-se, ali, mais um vínculo profissional/familiar.

Nesse período, Carolina ainda tentava sua vida com a carreira que tinha escolhido, trabalhava na agência de viagens e continuava distante dos negócios da família.

\section{O início de carreira}

Em março de 2007, Carolina percebeu que era hora de tentar outra carreira, outra profissão ou, talvez, outro segmento dentro da área de Turismo. Havia chegado ao seu limite, estava esgotada com o trabalho e frustrada por nem sempre conseguir impedir que imprevistos acontecessem e 
acabassem comprometendo o nível de qualidade nos pacotes de viagens oferecidos. Em virtude desses acontecimentos, e do desgaste da profissão, Carolina pediu demissão.

Nessa época, já estava casada com Alberto e não queria ficar desempregada, precisava dar um rumo a sua vida profissional. Foi nessa hora, então, que decidiu entrar no negócio da família. Não seria algo definitivo, mas somente uma passagem até que conseguisse uma nova oportunidade, entretanto, acabou sendo por um tempo maior do que o planejado. Naquele momento, a empresa também precisava de mais um funcionário para trabalhar no escritório e a vaga parecia perfeita. Carolina trabalhava com atividades relacionadas ao faturamento da empresa e, posteriormente, assumiu a gestão financeira, na qual atua até os dias atuais.

Por não ter formação na área financeira e não ter afinidade com os números, pois, até então, acreditava que não tinha habilidade para trabalhar nessa área, Carolina percebeu a necessidade de procurar novos cursos para aprimorar seus conhecimentos e contribuir ainda mais para o desenvolvimento da empresa. A princípio, uma vez que ainda estava aprendendo e se adaptando a um novo emprego, as rotinas financeiras pareciam ser desenvolvidas de maneira correta, mas, com o tempo e maior conhecimento prático e teórico, Carolina começou a perceber falhas na administração. Falhas não somente na área financeira, mas em toda a gestão da empresa, principalmente no que se referia aos assuntos familiares.

Como Carolina sempre trabalhou com foco nos resultados, e estava acostumada a trabalhar em organizações com regras rígidas, algumas atitudes mais flexíveis começaram a incomodá-la, assuntos familiares estavam sobressaindo-se em relação aos profissionais. Muitos problemas que deveriam ser resolvidos em casa foram levados para dentro da empresa, gerando discussões em torno destes, quando as discussões na empresa deveriam ser unicamente sobre assuntos empresariais.

No setor financeiro, Carolina conheceu realmente a empresa de seu pai e passou a identificar a real situação, por exemplo, quanto tinha a pagar e a receber. Essas informações possibilitaram o controle das entradas e saídas financeiras de modo mais adequado. $\mathrm{O}$ setor estava desorganizado, neste sentido, e o primeiro passo foi restringir as retiradas particulares e calcular, mês a mês, quanto a empresa faturava e qual era seu lucro real.

Carolina conseguiu estruturar melhor as contas, passou a separar o dinheiro da família do dinheiro da empresa, então todos, inclusive Sr. Ismael (dono e pai), começaram a receber salário e/ou pró-labore. Mudar a cultura de uma empresa, porém, não é tarefa fácil, ainda mais se, por trás desta, está sua família. Foram necessários reeducação de hábitos e comprometimento de todos para que percebessem a importância de separar as contas. Carolina aceitou o desafio e dedicou-se na reestruturação da área financeira.

Inicialmente parecia fácil, pois todos estavam dispostos a ajudar. Com o tempo, no entanto, Carolina percebeu que nem sempre todos estavam integrados no mesmo objetivo e, assim, começou a montar um diagnóstico da situação. Diogo, o irmão de Carolina, nunca teve outro emprego, sempre trabalhou com o pai, e nunca precisou cumprir regras e horários. Assim, não possuía comprometimento efetivo com os negócios. Inês, a mãe de Carolina, sempre foi protetora com os filhos, inclusive no ambiente profissional, o que prejudicava as atitudes na hora da tomada de decisão. Aquele era um momento de ser profissional e tratar todos da mesma maneira, o que não acontecia em diversas vezes. O pai, mesmo reconhecendo que a empresa deveria ser prioridade, sempre quis zelar pelo bem-estar da família e, assim, acabou deixando de estabelecer regras para o tratamento dos assuntos familiares dentro da empresa. Sua maior preocupação sempre fora evitar os 
conflitos, dessa forma, agiu apenas como pai, esquecendo-se, assim, de ser também o administrador do empreendimento.

Carolina identificou um dos principais problemas no relacionamento com o pai, que era a falta de controle da área financeira por parte do Sr. Ismael, já que este tentava ser um bom administrador, gerenciando conflitos, mas não tinha total controle do setor. Assim, quando qualquer membro da família precisava de ajuda financeira da empresa, o pai "fornecia" acesso ao caixa de maneira irrestrita.

Alberto e Carolina, mesmo depois de casados, sempre tiveram uma boa relação no trabalho. Carolina admirava e respeitava muito a conduta de Alberto na empresa, principalmente por partilharem das mesmas ideias quanto à estrutura organizacional, assim como sua dedicação, procurando aprimorar seus conhecimentos com a busca de cursos para auxiliar o desempenho do trabalho. Alberto decide acompanhar Carolina no curso de graduação em Ciências Contábeis, a fim de entender o processo da contabilidade, o qual, atualmente, é realizado por uma empresa terceirizada.

Carolina tinha uma visão crítica da empresa responsável pela contabilidade, pois falhas constantes começaram a atrapalhar e prejudicar o andamento dos negócios. A apuração dos impostos estava sendo feita baseada na tributação como se a empresa fosse enquadrada no simples, no entanto, ela era lucro presumido. Assustados diante de tantas falhas e riscos que estavam ocorrendo, Carolina e Alberto perceberam que era hora de fazer mais pela empresa e não ficar nas mãos de terceiros. Daí surgiu a ideia do curso de Ciências Contábeis, por meio do qual ganhariam conhecimento teórico e acadêmico. Segundo Carolina, os erros cometidos pela empresa terceirizada foram uma grande lição sobre a importância de cuidar de perto do setor e permanecer atento ao que pode acontecer. "Percebemos que seria realmente necessário acompanhar todos os processos e saber o que estava sendo feito para manter o controle e o conhecimento da área financeira".

\section{Pedras no caminho}

Os "problemas" enfrentados no negócio familiar fizeram com que Carolina repensasse seu futuro, ao ponto de não saber mais se realmente havia feito a escolha certa, mesmo sabendo que sua atuação no negócio contribuíra para a gestão atual, com a organização do setor financeiro por meio da implantação de ferramentas para aprimorar o processo de tomada de decisão.

Carolina já tentara convencer seu pai a realizar reuniões periódicas, das quais todos participassem com o objetivo de atrair o interesse de todos, principalmente de Diogo, pelo negócio. Sr. Ismael apoiou a ideia inicialmente, mas nunca houve empenho para a realização das reuniões. Em alguns momentos, Carolina achava que o problema poderia estar com ela, sentia que era muito exigente e dura demais em relação à empresa, preocupava-se demais com os resultados enquanto os demais familiares, na sua percepção, se mostravam desinteressados.

Ela estava ciente de que, mesmo com algumas dificuldades, este negócio "garantia" o necessário para sustentar financeiramente a família. Logo, mais do que qualquer um, ela sabia que a empresa precisava estar bem para que a família também estivesse, e muitas vezes tentava disfarçar seu descontentamento e manter-se distante das situações das quais discordava.

Este dilema acompanha Carolina constantemente: se sair, seus pais podem não gostar, mas, se ficar, pode se frustrar profissionalmente. Ela sabe que sua permanência na empresa contribui para o sucesso e crescimento do negócio. Se sair e uma pessoa sem vínculo com a família assumir o setor financeiro, talvez não consiga frear os impulsos familiares. 
Várias mudanças precisam ser realizadas na empresa visando aumentar sua participação no mercado, dentre elas está a comunicação, que, segundo Carolina, é informal, sem respeito à hierarquia e, muitas vezes, sem nenhum cuidado com o que se fala e onde se fala. Isso porque há intimidade suficiente entre os funcionários e a família, que esquecem que no ambiente de trabalho seu comportamento não deve ser o mesmo de casa. A comunicação não é somente verbal, mas escrita e corporal também. Nesse sentido, ela acredita que "devemos tomar muito cuidado no dia a dia para conseguirmos nos comunicar de modo eficaz e eficiente, pois possibilitará à empresa obter conhecimento e informações que permitam conquistar vantagem competitiva”.

Carolina afirma ainda que uma boa comunicação não é suficiente, é necessário também aprender a ouvir e tentar entender o outro lado da conversa. Esse ponto é importante para agregar valor à empresa, uma vez que, por meio da comunicação, obtêm-se informações que podem agregar valor aos negócios. Nesse sentido, Carolina refere-se tanto à comunicação interna quanto externa, seja no pedido do cliente, no prazo de entrega ou até mesmo nas condições de pagamento, todas as áreas devem melhorar a comunicação para que seus problemas internos não reflitam nas vendas e o cliente não perceba que existem falhas na prestação do serviço.

Quando falamos de clientes, fica evidente a importância do relacionamento com todos os stakeholders. A empresa de Carolina não tem apresentado problemas na comunicação com eles. Aliás, uma vantagem competitiva da empresa é o seu bom relacionamento com os parceiros externos, sendo o Sr. Ismael o principal responsável pelos bons resultados. A falha na comunicação, segundo Carolina, fica mais evidente com a informalidade existente no interior da organização.

Uma boa relação familiar é importante para o sucesso do negócio, assim como a gestão de pessoas é fundamental para que as relações se estreitem no âmbito profissional. Carolina acredita que seria importante definir quanto cada indivíduo está contribuindo para o sucesso da empresa. O Sr. Ismael, dono da empresa, não acata essas sugestões por receio de gerar conflitos. Para Carolina, ele não consegue visualizar que, apesar de serem filho, nora, genro e esposa, essas pessoas são seus funcionários e deveriam ter metas ou regras a cumprir. Em muitos momentos, ele possui dificuldades para assumir o papel de líder dentro da empresa. Todos deveriam, no entanto, ser mais comprometidos por iniciativa própria, pois este é o patrimônio de toda a família, e Carolina acredita que o importante é o desempenho de cada pessoa e não o seu grau de parentesco, todos precisam contribuir de modo semelhante para manter o bom relacionamento profissional e, consequentemente, o familiar, devendo o interesse coletivo prevalecer.

\section{A empresa... Ontem e hoje}

A empresa foi fundada em 5 de agosto de 2005, por iniciativa do pai de Carolina e com a ajuda de sua mãe, seu irmão e seu noivo. Sem ter realizado um plano de negócio ou até mesmo uma pesquisa de mercado, Sr. Ismael apostou em sua ideia e aventurou-se no novo empreendimento. Além dos familiares, inicialmente havia mais um funcionário; com o tempo, a empresa foi crescendo e hoje conta com oito funcionários, desconsiderando os familiares. Trabalha no mesmo ramo desde sua fundação, uma distribuidora de produtos descartáveis para supermercados. Assim como os funcionários, os clientes também foram aumentando e ganharam novas proporções, sendo atendidas grandes redes de supermercados dentro e fora do Estado. A carteira de clientes cresce a cada ano, as redes de supermercados e restaurantes são responsáveis por $80 \%$ do faturamento da empresa, que, em 2010, foi de 5 milhões de reais. 
Para Carolina, o Sr. Ismael abriu o negócio sem ter muito conhecimento em relação ao gerenciamento, tinha noções de venda e logística, mas como fazer a seleção de funcionários? Como gerenciar conflitos? Como controlar as finanças? Nem mesmo com o crescimento da empresa, Sr. Ismael preocupou-se com a estruturação das áreas. Desde sua fundação, nunca foi realizado qualquer planejamento ou diagnóstico de sua situação. Nunca houve uma tentativa de prever situações e preparar-se para elas, ele sempre aprendeu na prática com os erros que cometeu e sente-se capaz de conduzir o negócio dessa forma.

Por ter experiência profissional em empresas onde existem regras rígidas, Carolina acredita que, pelo fato de a empresa não possuir regras claras, tão pouco o desenho dos processos de trabalho de cada área estar definido e documentado, as funções e atribuições de cada colaborador podem ser prejudicadas e até mesmo a rede hierárquica de subordinação, em alguns momentos, pode ser desrespeitada.

Os membros da família, no entanto, têm funções distintas na empresa, cada um trabalha de acordo com seu perfil, competências e com as necessidades que aparecem. A função de cada um e sua hierarquia são apresentadas na figura no Anexo 1, a qual evidencia que a gestão da empresa está exclusivamente nas mãos dos familiares. Sr. Ismael, o dono, toma as decisões mais importantes e exerce o papel de líder, definindo seu rumo, os objetivos e, por sua posição também de pai, buscando a melhor forma de todos estarem bem, muitas vezes independentemente das consequências que determinadas ações podem gerar para a empresa.

Alberto, o gerente, faz negociações importantes, busca as melhores formas de compra para a empresa, analisa clientes e auxilia na tomada de decisões dos demais funcionários. Inês, responsável pelo faturamento, organiza os pedidos por ordem de chegada, importância e quantidade de produtos para serem faturados, além do agendamento de notas a serem entregues. Carolina atua no setor financeiro, no qual é responsável por contas a pagar, a receber, pagamentos de funcionários, cobranças, orçamentos, e também contribui nas tomadas de decisões. Diogo é representante comercial, possui uma carteira de clientes fixa, atende os supermercados de Florianópolis até Blumenau.

\section{Relação familiar dentro da empresa}

Os níveis hierárquicos apresentados nem sempre são respeitados e, em uma estrutura familiar, linhas invisíveis são criadas com facilidade. Para Carolina, por que Diogo resolveria algum problema com Alberto se tem intimidade suficiente para chegar até seu pai? Aliás, esse tem sido um tema constante de brigas, já que, na vida pessoal, Diogo e Alberto não mantêm um bom relacionamento, causado, em grande parte, por problemas profissionais. Carolina retrata desta forma a situação:

Meu pai e o Alberto sempre tiveram uma boa relação, Alberto foi um parceiro para as discussões na abertura da empresa e sempre atuou como conselheiro na tomada de decisões. Diogo não aceita essa relação, demonstrando certo incômodo em algumas situações, o que pode gerar, de certa forma, sua aparente desmotivação e o fato de não buscar assumir muitas responsabilidades. Na minha percepção, a situação se agravou quando a esposa de Diogo, que também já trabalhou na empresa, foi demitida. Embora tenha sido o meu pai o responsável pela demissão, até hoje Diogo e sua esposa culpam Alberto, achando que, de alguma forma, ele fez pressão para que isso acontecesse.

Carolina queixa-se, principalmente, pelo fato de o irmão não buscar aperfeiçoamento e, assim, se desenvolver nas atividades sob sua responsabilidade. Outras situações, como a redução do salário 
de Diogo e a retirada de benefícios, fizeram com que a situação se tornasse insustentável. Carolina está sempre no meio dessas discussões e se envolve na tentativa de acalmar os ânimos, objetivando a compreensão de que se trata de uma situação profissional e existem limites a serem respeitados. Tenta mostrar que, acima de qualquer interesse pessoal, há uma empresa precisando de profissionais competentes para continuar saudável, gerando empregos e sustentando toda a família, por isso todos deveriam primar pelo interesse da empresa e não só por objetivos pessoais.

Os desentendimentos entre os familiares estão trazendo malefícios para a organização sem que sejam percebidos. Carolina relatou que, algumas vezes, após essas brigas, alguns clientes precisaram ser atendidos, reuniões com fornecedores precisaram ser feitas e o clima não estava propício. Ela se pergunta até onde isso pode ter prejudicado as negociações, de maneira direta ou indireta, e até quando será possível continuar assim.

Cada desentendimento faz com que Carolina reveja toda a sua situação dentro do contexto da empresa e volte a pensar em desistir e buscar um novo emprego. Nesses momentos, surge o medo de deixar tudo para trás, pois os demais integrantes da família podem não conseguir manter a empresa sem contar com o seu envolvimento e comprometimento. Em empresas familiares, sempre ocorre certa insegurança em colocar alguém sem vínculo com a família em um cargo de confiança, como o responsável pelo setor financeiro, por exemplo.

Carolina tem consciência de que não se trata apenas de uma empresa e preza pelo patrimônio de sua família, investido no negócio. Esse é o interesse comum de sua família, mas o que mais a incomoda é a relação profissional entre os membros. Não é fácil lidar com os conflitos familiares, conseguir manter uma relação formal e respeitar as regras. Por mais que queiram manter o profissionalismo, a vida pessoal acaba sendo incorporada à da empresa.

Mesmo misturando a vida pessoal e a profissional, existe confiança em relação à gestão dos responsáveis por cada área, "ninguém vai roubar de si próprio ou deixar de fazer o melhor possível", mas o melhor possível, sob a visão particular de cada participante do negócio, diverge bastante. Essas divergências são normais, e acontecem em todas as empresas, o problema, realmente, na visão de Carolina, está na gestão do Sr. Ismael. Ele, como líder, deveria trabalhar melhor as divergências de opiniões, pois é evidente que Alberto e Diogo não compartilham da mesma opinião nem dos mesmos objetivos. Mas, mesmo com esses conflitos, a empresa trabalha com maior flexibilidade, comparando-se a outras empresas, e isso tem proporcionado bons resultados financeiros.

\section{A relação de Carolina com o pai}

Carolina e o Sr. Ismael sempre tiveram uma boa relação como pai e filha, com muito carinho e respeito, e sempre conversaram com respeito mútuo. Claro que, como a maioria dos pais, Sr. Ismael impôs alguns limites na educação de Carolina, mas nunca interferiu diretamente nas suas escolhas. Quando ela decidiu fazer faculdade, deu-lhe a liberdade de escolher o curso que julgasse melhor e a apoiou financeiramente, vibrou com cada conquista e, sempre que pôde, esteve presente.

Carolina possui admiração pelo pai, por sua conduta e seu caráter. É um homem muito trabalhador e dedicado ao que faz, nunca mediu esforços para dar o melhor a sua família. Desde que entrou na empresa e eles tiveram a oportunidade de trabalhar juntos, Carolina tem despertado a atenção de seu pai, mostrando um bom desempenho. Ele está descobrindo nela alguém para ficar no seu lugar, principalmente depois que percebeu o interesse de Carolina pela empresa.

Aliás, esse processo de sucessão ainda não está claro na empresa. Sr. Ismael já conversou diversas vezes com a filha sobre seu desejo de que ela assuma os negócios na sua ausência, mas 
nunca explicitou isso para os demais familiares. Carolina sente falta de um planejamento formal e da comunicação do desejo do pai para os demais membros da família. O interesse de Carolina em se aprofundar nos assuntos empresariais e buscar formação, além de sua postura, faz com que o pai se convença sobre sua futura direção nos negócios, mas, por alguma razão, ele apresenta receio em evidenciar isso aos demais.

Para Carolina, podem ocorrer problemas futuros pelo fato de o Sr. Ismael não deixar claro para os outros membros da empresa e família seu desejo de que a filha seja a administradora do empreendimento na sua ausência, principalmente quando as decisões envolvem a área financeira. "Acredito que, talvez pelo mau relacionamento entre Alberto e Diogo, meu pai acredite que algumas das minhas decisões sejam tomadas pelo emocional para não beneficiar Diogo, mas isso me deixa ainda mais desmotivada em função da extrema informalidade entre os membros da família."

Carolina vive uma situação complexa, pois, ao conhecer o desejo do pai, fica orgulhosa por ver seu trabalho reconhecido e se sente ainda mais motivada a buscar novos conhecimentos para estar realmente preparada, caso venha a assumir a direção da empresa.

\section{Empresa x Família}

Analisando todas as situações que se apresentam na empresa e na família, Carolina começa a se questionar se a empresa deve servir à família ou a família deve servir à empresa. O que deve de fato prevalecer? O que deve vir em primeiro lugar? Afinal, uma empresa familiar foi feita para sustentar os seus membros ou estes devem fazer com que a empresa prevaleça, independentemente de suas vidas pessoais? Carolina relembra momentos em que a empresa serviu com o propósito de ajudar a família, como no caso da festa de formatura de Diogo ou na troca de carro do Sr. Ismael, entre outros momentos.

Não somente financeiramente, no entanto, a empresa pode auxiliar a família, pois são oferecidas vantagens que não são possíveis em outros empregos. Há empregabilidade para toda a família (pais e filhos), férias e folgas de acordo com a necessidade do familiar e não necessariamente da empresa. Assim, Carolina se questiona se não está com um objetivo diferente dos demais familiares para a empresa. Qual o verdadeiro propósito para ela existir? Não está Carolina exigindo demais dela e dos outros membros da família?

Percebendo que, apesar de todas as mudanças que Carolina julga necessárias, a empresa ainda está crescendo e com boa lucratividade, ela volta a se questionar do quanto realmente precisa ser melhorado e até onde vale a pena esse desgaste familiar. Talvez fosse melhor Carolina encarar o jeito de sua família de administrar um negócio como algo que não pode mudar e se beneficiar, ela mesma, das vantagens que a empresa pode trazer.

Ao requisitar reuniões familiares para discutir assuntos administrativos, ela acredita que assuntos familiares podem ser colocados em pauta, para que todas as questões pendentes sejam resolvidas e esclarecidas e, ao menos se não houver uma mesma visão de estratégia comercial, que haja uma harmonia familiar dentro da empresa.

Conversando com amigos, Carolina descobriu que não só ela vive esses momentos de dúvidas e incertezas na empresa da família. Algumas amigas que trabalham com seus pais passam pelos mesmos questionamentos e dúvidas. Percebem também que algumas mudanças devem ser feitas e têm desentendimentos familiares, mas todos têm um objetivo comum: zelar pelo patrimônio. Independentemente de estar confortável ou não na empresa e na função que ocupam, todos querem 
ver seu patrimônio perdurar e fazer parte disso. Algumas dificuldades e tensões acabam sendo inevitáveis.

Ela também percebeu que alguns amigos passam por outra situação: trabalham em empresas familiares, mas não fazem parte da família. Algo que possivelmente pode acontecer com ela, caso resolva sair da empresa da família. Essa também é uma situação desconfortável, pois faz a pessoa pensar quando chegará a um cargo de gerência ou subirá de posto quando existem familiares na sua frente para ocupar esses cargos. Se as perspectivas não parecem as melhores na sua empresa, ela passa a perceber que, fora dela, também podem ser muito difíceis, ou seja, fazer os negócios de sua família prosperarem é tão difícil quanto prosperar em uma outra empresa.

Em conversas com amigas, Carolina percebeu que os problemas que acontecem na empresa do pai ocorrem também em outras empresas. Se não pelo vínculo familiar, pela ganância ou pela concorrência interna que existe entre os colegas de trabalho. Para as amigas de Carolina, cada empresa tem suas peculiaridades e suas deficiências, o profissional que estiver trabalhando nela é quem terá que saber administrá-las de modo que consiga conviver com as diferenças existentes.

Carolina, então, começa a pensar em outras possibilidades: será mesmo ruim trabalhar na empresa do pai? Qual o problema em administrar seu tempo de acordo com o que lhe convém? Ela quer trabalhar em um local onde tenha que cumprir horário? Talvez ela tenha uma vida profissional da qual possa se privilegiar em várias questões e não esteja sabendo aproveitar. Muitos profissionais gostariam de ter o controle do seu próprio tempo, podendo conciliar trabalho, cursos e outras atividades com o horário de trabalho.

\section{Os dilemas de Carolina}

Os dilemas de Carolina aumentaram após ela procurar especialização no ramo empresarial e entender melhor a complexidade dos negócios. Isso ocorreu no segundo semestre de 2010, quando iniciou seu curso de MBA em finança empresarial. Começou a fazer analogias com os temas abordados em aula, com as leituras que passou a realizar e começou a questionar a administração da empresa. Passou também a ter um discernimento sobre os processos e a discordar da abordagem paternalista dentro da organização. Em suas tentativas de convencer os demais a apoiar suas ideias, entretanto, Carolina frustrou-se ao tentar mudar a relação familiar dentro da empresa.

$\mathrm{Na}$ ocasião da formatura de Diogo, Carolina comenta o fato que considerou a gota d'água, pois demonstrou a atitude paternalista prevalecendo à de líder:

Meu pai solicitou uma retirada da conta da empresa para patrocinar a formatura do Diogo. Com isso, percebi que o caminho para o profissionalismo da empresa, como gostaria e julgava ser o correto, estava cada vez mais longe de acontecer. Foi quando senti que precisava tomar uma atitude e fazer algo em prol do meu futuro profissional, para, de uma vez por todas, tirar a dúvida de seguir ou não carreira dentro da empresa de minha família.

Em sua essência, Carolina possui um perfil moldado por experiência profissional fora do ambiente familiar, com regras, normas e condutas empresariais que devem ser cumpridas. O perfil do Sr. Ismael, como pai e não como administrador, é o que mais influencia nos conflitos existenciais que assolam os pensamentos de Carolina, pois, para ela, a gestão de seu pai deveria ter como base a liderança de seus subordinados e não relevar e passar a mão na cabeça dos filhos. A postura de Carolina diante da família interfere e muito na empresa, principalmente na relação entre Diogo e 
Alberto: "Ele deveria incentivar a descentralização do processo decisório e ser menos paternalista, acompanhar os processos para depois tomar decisão ou apoiar alguém".

Outro problema apontado por Carolina é a comunicação, não somente pelo fato de Diogo levar determinadas situações diretamente ao pai quando deveria conversar com Alberto, seu superior imediato dentro da hierarquia existente. Carolina queixa-se pelo fato de não existirem reuniões ou conversas para acompanhamento do desempenho das áreas ou indivíduos e acredita que o desempenho seria melhor se houvesse metas para cada departamento e estas fossem acompanhadas e disseminadas para todos os envolvidos no negócio da família.

Carolina tem muitas ideias para melhorar a gestão da empresa, ao mesmo tempo possui receio de tentar se impor e, algumas vezes, acaba nem as apresentando para não gerar mais conflitos, principalmente quando a situação envolve seu irmão. Essa falta de diálogo que existe na gestão empresarial do Sr. Ismael interfere muito na convivência dos irmãos "colegas de trabalho", pois o pai não deixa claro ao filho seu descontentamento em relação às suas atividades profissionais, e os problemas que são passados a ele não são levados a Diogo. Carolina está muito preocupada em relação à situação financeira da família por conta de várias conversas que tem com seu irmão a respeito de suas contas pessoais, pois, em algumas ocasiões, ela vê seu irmão retirando dinheiro da empresa com o consentimento de seu pai para pagar contas pessoais, como: apartamento, móveis etc. Outra dificuldade que Carolina também observa e não expõe a ninguém é a relação que a mãe tem com os funcionários. Esta está sempre cedendo e ajudando a todos, e isso acaba enfraquecendo a autoridade dos gestores Alberto e Sr. Ismael, pois os colaboradores acabam se viciando em pedir tudo a ela, que sempre concorda em ajudá-los.

Em suas funções, Carolina conseguiu quebrar uma barreira por meio da procura por informações para auxiliá-la no gerenciamento financeiro e está sempre atenta a novas oportunidades e possíveis crises, às formas de investimentos e à formação do patrimônio. Sempre procura propor ideias, resolver problemas para manter um planejamento financeiro e orçar os gastos.

Acredita que estudar e procurar se cercar de pessoas que também estudam é uma boa forma de manter-se bem no trabalho. "O estudo enriquece muito, principalmente para desenvolver ideias para implantar na empresa, não apenas pelas disciplinas trabalhadas nos cursos, mas pela troca de experiências entre os colegas. Nesse ambiente, as ideias e as críticas surgem mais rapidamente."

Carolina crê que o mais importante na função ocupada é o senso de responsabilidade, seja com a organização ou com os funcionários, sempre em busca do que é correto em todos os sentidos. "Precisei ampliar minha visão da empresa como um todo, e sempre busquei ter uma visão mais aberta a respeito do negócio e de todos os setores e passar essa motivação para os demais." Para Carolina, o Sr. Ismael e Alberto compartilham desse pensamento, pois tentam construir uma noção de sucesso com base em suas percepções da empresa e do mercado, e, como ocupam responsabilidades de destaque, a visão holística é fundamental para eles na tomada de decisão.

Em contrapartida, Carolina acha que Diogo e Inês são mais "acomodados", preocupam-se apenas com seu desempenho na função ocupada, que se restringe a tirar e faturar pedidos, respectivamente. Na percepção de Carolina, Diogo dedica-se à empresa, mas, por não ter outras experiências profissionais, não consegue discernir o ambiente profissional e o familiar como sendo coisas distintas e, com frequência, toma decisões por impulso.

Carolina acredita que não basta administrar bem a empresa para continuar crescendo, é necessário ter visão de futuro e tentar inovar, não apenas nos produtos, mas nos processos, na gestão e nos relacionamentos. Ela se sente frustrada, no entanto, quando acredita ter uma boa ideia e, ao 
apresentá-la, não receber atenção e apoio para colocá-la em prática. Muitas vezes, os demais membros da família estão preocupados apenas com a comercialização dos produtos.

Por isso, muitas vezes, Carolina se depara com o dilema de continuar ou não na empresa de seu pai. “Às vezes penso que meu esforço não é visto e nem ao menos tem importância. O que será que está acontecendo? Será que só eu enxergo os erros? Só eu me preocupo com o amadurecimento e o crescimento da empresa? Ou será que estou errada, e não penso no bem-estar da família?”

\section{Hora de decisão}

É difícil decidir algo com tantas dúvidas, será que, mesmo depois de tanto esforço e dedicação, "vale a pena investir na carreira da empresa familiar? As brigas e as discussões podem ser deixadas de lado e separar o lado pessoal do profissional? Vale a pena se desgastar com seus familiares em troca de uma carreira?”. Essa é uma decisão que Carolina terá que tomar brevemente, antes que se crie uma relação de dependência mútua.

Não é fácil para ela, porém, deixar os negócios da família, e, ao mesmo tempo, não pode se privar de ter uma carreira em outro lugar só para satisfazer a vontade dos pais. Esse dilema está tomando muito mais o tempo de Carolina que as atividades profissionais. E isso pode refletir e muito no seu desempenho profissional e na sua vida pessoal. 


\section{Anexo 1}

Organograma da empresa e relações familiares

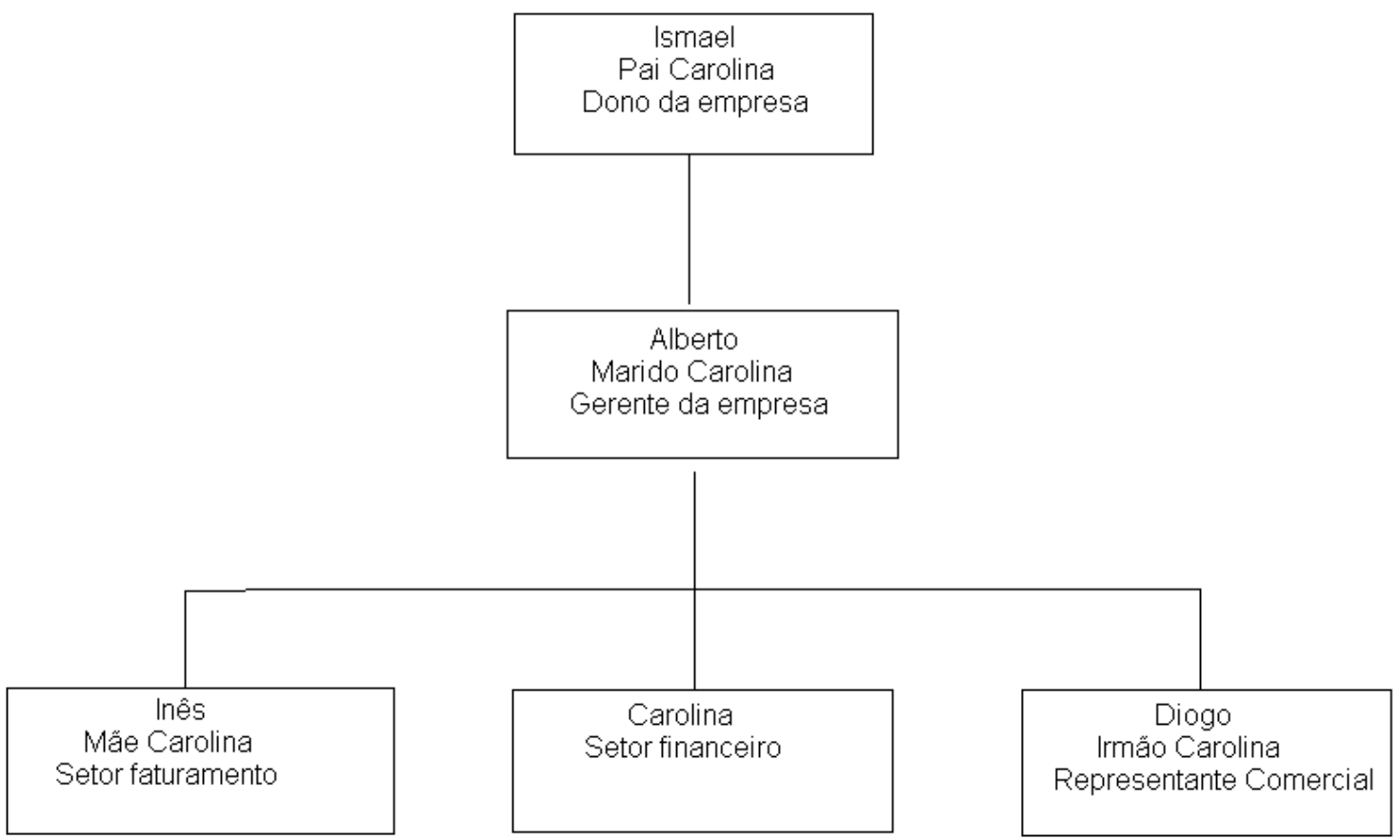

